\title{
An estimate of the veteran population in England: Based on data from the
}

2007 Adult Psychiatric Morbidity Survey

Charlotte Woodhead et al. ${ }^{1}$

King's College London

Background: The health and well-being of military veterans has recently generated much media and political interest. Estimating the current and future size of the veteran population is important to the planning and allocation of veteran support services. Methods: Data from a 2007 nationally representative residential survey of England (the Adult Psychiatric Morbidity Survey) were extrapolated to the whole population to estimate the number of veterans currently residing in private households in England. This population was projected forward in two ten-year blocks up to 2027 using a current life table.

Results: It was estimated that in 2007,

$3,771,534$ (95\% Cl: 2,986,315-

$4,910,205)$ veterans were living in residential households in England. By 2027, this figure was predicted to decline by 50.4 per cent, mainly due to large reductions in the number of veterans in the older age groups (65-74 and 75+ years).

Conclusion: Approximately three to five million veterans are currently estimated to be living in the community in England. As the proportion of National Service veterans reduces with time, the veteran population is expected to halve over the next 20 years.

\section{Introduction}

The US decennial census has included questions on military service since 1840, identifying those who are service veterans; that is, individuals who have formally left service with the US Armed Forces. ${ }^{1}$ This has enabled reliable measurement of the size of the US veteran population to be estimated. ${ }^{1}$ Although the UK census does not collect this information on military service, a UK-based veteran charity (the Royal British Legion (RBL)), on the basis of data from a 2005 nationally representative Research Surveys of Great Britain (RSGB) omnibus survey, recently estimated the size of the ex-service community (veterans and their dependents). They estimated that there are approximately 4.8 million veterans currently living in private residential households in the UK (Great Britain and Northern Ireland), ${ }^{2}$ of which approximately 3.9 million were residing in private households in England (personal communication). The RBL forecast the size of the veteran population up to 2020 in a subsequent publication. ${ }^{3}$ They predict that the veteran population will decline from approximately 4.8 million to 3.1 million by 2020 . Such estimates are necessary for the planning and allocation of resources to identify and assist with veterans' needs, such as help with pensions and benefits, housing, medical care and skills assessments.

1 This article was produced by: Charlotte Woodhead, Academic Centre for Defence Mental Health, King's College London; Andy Sloggett, Centre for Population Studies, London School of Hygiene \& Tropical Medicine; Issy Bray, Health Information and Surveys Division, DASA; Jason Bradbury, Health Information and Surveys Division, DASA; Sally McManus, National Centre for Social Research; Howard Meltzer, University of Leicester, Terry Brugha, University of Leicester; Rachel Jenkins, WHO Collaborating Centre for Research and Training in Mental Health and Section of Mental Health Policy, Institute of Psychiatry, King's College London; Neil Greenberg, Academic Centre for Defence Mental Health, King's College London; Simon Wessely, Academic Centre for Defence Mental Health, King's College London; Nicola Fear, Academic Centre for Defence Mental Health, King's College London. 
The current study uses a 2007 nationally representative survey of adults in England ${ }^{4}$ to estimate the number of veterans. The aims of this study are: (1) estimate the current number of veterans in England by age and sex, and (2) to forecast the future population of veterans by age and sex.

\section{Methods}

\section{Data collection and sample}

Analyses were carried out using data collected for the 2007 Adult Psychiatric Morbidity Survey (APMS), ${ }^{4}$ a representative probability sample of adults living in private households in England. It used a multi-stage sampling design, stratified by socio-economic status and geographical region. In total, 7,461 adults responded to the first stage of the survey, corresponding to a response rate of 57 per cent. Full details of the survey methodology are available elsewhere. ${ }^{4}$

For the purposes of these analyses, the following exclusions were made: proxy interviews $(n=36)$; veterans reporting improbable ages of service (such as joining before age 16 or after age 55 years) $(n=42)$; respondents who were still currently serving $(\mathrm{n}=22)$; and, non-veterans $(\mathrm{n}=6,560)$. The final sample included 801 veterans representing 10.8 per cent of the original study sample.

\section{Veteran population size estimation}

The proportion (and 95\% confidence interval (CI)) of veterans by age and sex represented in the sample was multiplied by the total estimated mid-2007 population of England aged over 16 years ${ }^{5}$ to estimate the number of veterans in each age and sex group in the population. These were summed to produce an estimate (and CI) of the current veteran population of England. Estimates took into account the weighting, clustering and stratification inherent in the survey design. Weighting accounted for non-response based on the difference between the sample and mid-year estimates, and differential selection probabilities. Clusters were postcode sectors, and were stratified on the basis of socio-economic status within regional areas. ${ }^{4}$ The proportion of veterans aged $16+$ estimated to be living in England was multiplied by the number of people aged 16+ in England living in communal establishments, using data from the 2001 Census, ${ }^{6}$ in order to approximate the degree of underestimation in the current veteran population calculations. Analyses were carried out using the statistical software package STATA (version MP10.1) and Excel.

\section{Veteran population projection}

(Notes a-e in superscript refer to Box One). A crude projection of the veteran population by age group and sex, to the calendar years 2017 and 2027, was made using the 2007 veteran population point estimate as baseline figures. A current life table for England ${ }^{7}$ was used to project the baseline population in two ten-year blocks. ${ }^{8}$ From the life table, ${ }_{10} \mathrm{~L}_{\mathrm{x}}{ }^{\mathrm{a}}$ was derived from the equation: $10 / 2\left(1_{x}+1_{x+n}\right) \cdot{ }^{b}$ For the last open-ended age group (75+ years) ${ }_{\infty} \mathrm{L}_{\mathrm{x}}$ was calculated by the equation: ${ }_{\infty} \mathrm{L}_{\mathrm{x}}=1{ }_{\mathrm{x}} /{ }_{\infty} \mathrm{M}_{\mathrm{x}}$, where ${ }_{\infty} \mathrm{M}_{\mathrm{x}}=\left({ }_{\infty} \mathrm{D}_{\mathrm{x}} /{ }_{\infty} \mathrm{P}_{\mathrm{x}}\right) \mathrm{k} \cdot{ }^{\mathrm{c}}$. The function ${ }_{10} \mathrm{~L}_{\mathrm{x}}$ was used to determine the ten-year survival ratio $\left({ }_{10} \mathrm{~S}_{\mathrm{x}}\right)^{\mathrm{d}}$ - derived from the equation: ${ }_{10} \mathrm{~S}_{\mathrm{x}}={ }_{10} \mathrm{~L}_{\mathrm{x}+10} /{ }_{10} \mathrm{~L}_{\mathrm{x}}$, for each ten-year age and sex group (for example, males aged 25-34 years). The survival ratio was multiplied by the baseline population in that group to estimate the population size for that age and sex group ten years later (that is, males aged 35-44 years). The survival ratio for the last openended age group (75+ years) was calculated using $\mathrm{T}_{75} / \mathrm{T}_{85}{ }^{\mathrm{e}}$ in order to project the $75+$ age group into an $85+$ years open-ended age group. This group was then added into the $75+$ age group as current estimates were not broken down into further age categories after age 75 years. ${ }^{8}$

As the first age group (16-24 years) was survived forward by ten years into the successive age group (25-34 years), it was replaced by

\section{Box one}

\section{Veteran population projection, explanation of terms used}

${ }_{10} L_{x}=$ the average number of the radix population living between ages $x$ and $x+10$ years.

${ }^{b} I_{x}=$ number of survivors of the radix population aged exactly $x$ years; $n=$ number of years in interval.

c $M_{x}=$ the age-specific death rate; $D_{x}=$ number of deaths in the last age group; ${ }_{\infty} P_{x}=$ population in the last age group and $k=1$ if the age-specific death rate is calculated per person.

${ }^{d}$ The proportion of a cohort that survives from one age interval to the next.

e $T_{x}=$ the total population aged $x$ and over, calculated from the sum of $L_{x}$ values from age $x$ to the highest age in the life table

an estimate of the number of personnel leaving the services becoming veterans in the youngest age group (16-24 years) during the ten-year period. Similarly, the estimated numbers of additional veterans added to the 'pool' in each age group throughout each ten-year period were added to the projected population estimate in each age and sex category. The number of new veterans was estimated using military outflow data obtained from Defence Analytical Services and Advice (DASA). ${ }^{9}$ This provided information on outflow from the military by sex and age up to 55+ years from 1999 to 2006 during which time outflow rates remained fairly stable. An annual average outflow rate was estimated for each age and sex group (using the military strength for that age and sex category as a denominator) and multiplied by ten to estimate the number of new veterans over a ten-year period. It was assumed that all those leaving the forces in the 55+ age group entered the veteran population group aged 55-64 years as it is unlikely that personnel leave the services after age $65 .{ }^{9}$

It was assumed that the mortality rate would not change over the projection period and that veterans would have the same mortality rate as the general population, as represented in the current life table. ${ }^{7}$

Projected values are presented to the nearest 100 veterans due to potential error inherent in the estimation, and baseline figures may differ to the estimate of the current population due to rounding. Projections were carried out using Excel.

\section{Results}

\section{Current population estimation}

The total number of community dwelling veterans (including national service veterans) in England (aged 16+ years) was estimated to be 3,771,534 (95\% CI: 2,986,315-4,910,205) (See Table 1). Of these 3.8 million veterans, 473,204 (95\% CI: 295,440-799,722) are female (12.5 per cent, $95 \%$ CI: $9.9-16.3$ per cent).

Using an estimate of the mid-2007 England population aged 16+ as $41,436,300$ people, ${ }^{5}$ community dwelling veterans comprise 9.1 per cent (95\% CI: 7.2-11.9 per cent) of the English population aged 16+ years. The additional number of veterans living in communal establishments was estimated to be 28,437 (95\% CI: 23,200-35,439) (male veterans) and 4,761 (95\% CI: 2,972-8,046) (female veterans). 


\begin{tabular}{|c|c|c|c|c|c|c|}
\hline \multirow[b]{2}{*}{$\begin{array}{l}\text { Age group } \\
\text { (years) }\end{array}$} & \multicolumn{2}{|c|}{ Male } & \multicolumn{2}{|c|}{ Female } & \multicolumn{2}{|c|}{ Total } \\
\hline & $\begin{array}{l}\text { Estimated No. } \\
\text { veterans }\end{array}$ & $\begin{array}{l}95 \% \text { Confidence } \\
\text { linterval }\end{array}$ & $\begin{array}{l}\text { Estimated No. } \\
\text { veterans }\end{array}$ & $\begin{array}{l}\text { 95\% Confidence } \\
\text { linterval }\end{array}$ & $\begin{array}{c}\text { Estimated No. } \\
\text { veterans }\end{array}$ & $\begin{array}{l}\text { 95\% Confidence } \\
\text { linterval }\end{array}$ \\
\hline $16-24$ & 58,011 & $22,376-149,171$ & 39,365 & $14,088-116,022$ & 97,376 & $36,464-265,193$ \\
\hline $25-34$ & 182,320 & $116,022-281,767$ & 26,934 & $11,602-62,155$ & 209,254 & $127,624-343,922$ \\
\hline $35-44$ & 356,352 & $277,623-464,087$ & 41,436 & $21,961-78,729$ & 397,788 & $299,584-542,816$ \\
\hline $45-54$ & 319,060 & $236,187-435,081$ & 66,298 & $35,635-116,022$ & 385,358 & $271,822-551,103$ \\
\hline $55-64$ & 356,352 & $273,480-464,087$ & 58,011 & $33,978-91,160$ & 414,363 & $307,458-555,247$ \\
\hline $65-74$ & 940,604 & $808,008-1,089,775$ & 25,691 & $12,431-53,867$ & 966,295 & $820,439-1,143,642$ \\
\hline $75+$ & $1,085,631$ & $957,179-1,226,515$ & 215,469 & $165,745-281,767$ & $1,301,100$ & $1,122,924-1,508,282$ \\
\hline Total & $3,298,330$ & $2,690,875-4,110,483$ & 473,204 & $295,440-799,722$ & $3,771,534$ & $2,986,315-4,910,205$ \\
\hline
\end{tabular}

Note: Estimates are rounded to the nearest whole number.

\begin{tabular}{|c|c|c|c|c|c|c|c|c|c|c|c|c|}
\hline \multirow[b]{2}{*}{$\begin{array}{l}\text { Age group } \\
\text { (years) }\end{array}$} & \multicolumn{6}{|c|}{ Males } & \multicolumn{6}{|c|}{ Females } \\
\hline & 2007 & 2017 & $\begin{array}{c}\% \text { change } \\
2007-2017\end{array}$ & 2027 & $\begin{array}{c}\% \text { change } \\
2017-2027\end{array}$ & $\begin{array}{c}\% \text { change } \\
2007-2027\end{array}$ & 2007 & 2017 & $\begin{array}{c}\% \text { change } \\
2007-2017\end{array}$ & 2027 & $\begin{array}{c}\% \text { change } \\
2017-2027\end{array}$ & $\begin{array}{r}\% \text { change } \\
2007-2027\end{array}$ \\
\hline $16-24$ & 58,011 & 101,600 & 75.1 & 101,600 & 0.0 & 75.1 & 39,365 & 11,800 & -70.0 & 11,800 & 0.0 & -70.0 \\
\hline $25-34$ & 182,320 & 109,000 & -40.2 & 152,300 & 39.7 & -16.5 & 26,934 & 46,900 & 74.1 & 19,400 & -58.6 & -28.0 \\
\hline $35-44$ & 356,352 & 225,300 & -36.8 & 152,800 & -32.2 & -57.1 & 41,436 & 28,900 & -30.3 & 48,700 & 68.5 & 17.5 \\
\hline $45-54$ & 319,060 & 361,400 & 13.3 & 233,500 & -35.4 & -26.8 & 66,298 & 40,900 & -38.3 & 28,500 & -30.3 & -57.0 \\
\hline $55-64$ & 356,352 & 305,300 & -14.3 & 345,300 & 13.1 & -3.1 & 58,011 & 63,900 & 10.2 & 39,400 & -38.3 & -32.1 \\
\hline $65-74$ & 940,604 & 304,200 & -67.7 & 260,600 & -14.3 & -72.3 & 25,691 & 52,400 & 104.0 & 57,700 & 10.1 & 124.6 \\
\hline $75+$ & $1,085,631$ & 922,400 & -15.0 & 373,200 & -59.5 & -65.6 & 215,469 & 87,600 & -59.3 & 45,400 & -48.2 & -78.9 \\
\hline Total & $3,298,330$ & $2,329,200$ & -29.4 & $1,619,300$ & -30.5 & -50.9 & 473,204 & 332,400 & -29.8 & 250,900 & -24.5 & -47.0 \\
\hline
\end{tabular}

Note: Number (n) and per cent change are shown.

Estimates are rounded to the nearest 100.

\section{Population projection}

The total number of veterans was forecast to decline by 29.4 per cent between 2007 and 2017 and by 29.7 per cent between 2017 and 2027. The veteran population was forecast to reduce overall between 2007 and 2027 by 50.4 per cent.

The projected male veteran population was 50.9 per cent lower in 2027 than the current 2007 population estimate $(\sim 3,298,300$ people). For male

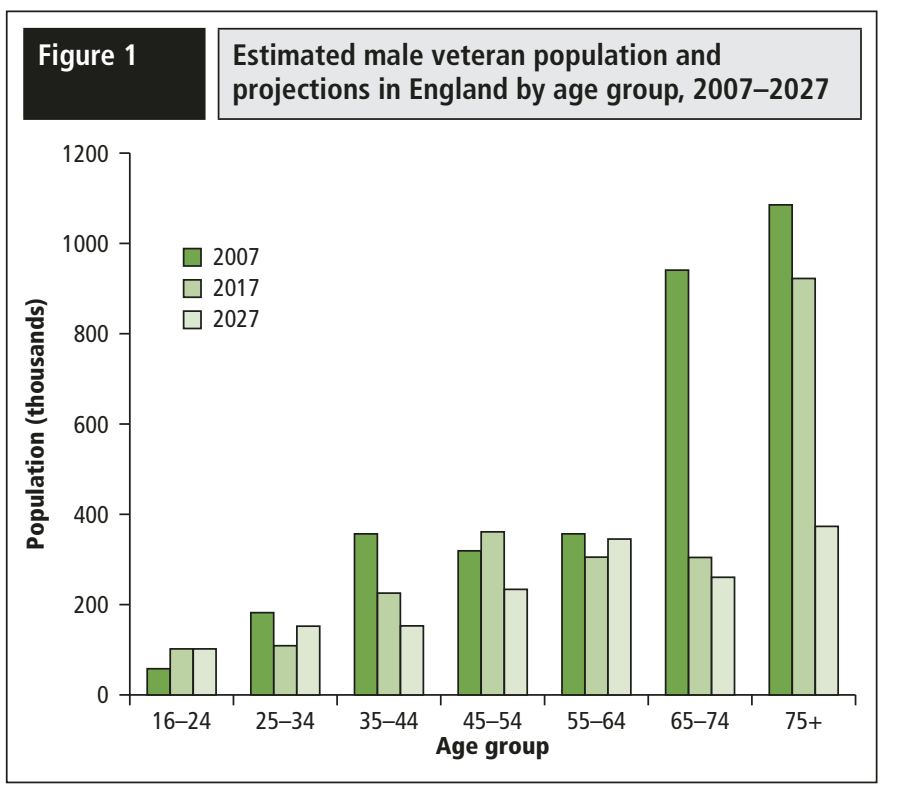

veterans, the population in all age groups was predicted to decline between 2007 and 2027, except the 16-24 year group which was estimated to increase by 75.1 per cent. The greatest reductions were forecast to affect the $35-44,65-74,75+$ years age groups ( -57.1 per cent, -72.3 per cent and -65.6 per cent respectively) (See Table 2 and Figure 1).

The total female veteran population was forecast to reduce by 47.0 per cent from approximately 473,200 to 250,900 women. Large

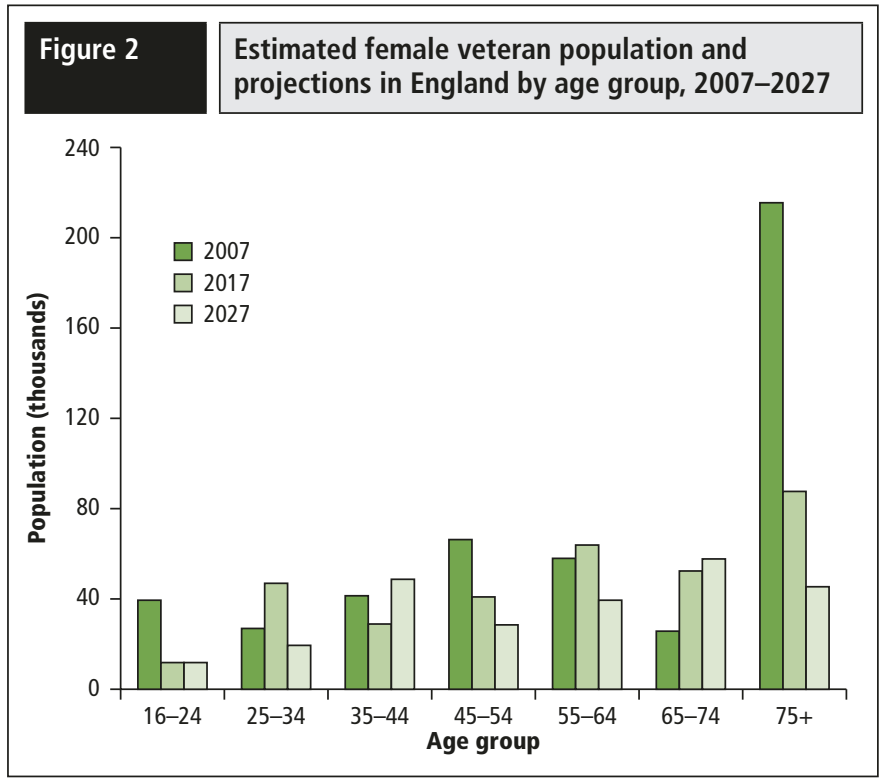


reductions were predicted to occur in the $16-24,45-54$ and $75+$ years age groups ( 70.0 per cent, 57.0 per cent, and 78.9 per cent respectively), while the 35-44 and 65-74 year age group populations were expected to increase (by 17.5 per cent and 124.6 per cent respectively) (See Table 2 and Figure 2).

\section{Discussion}

The results of this study estimate the current population of veterans in England to be approximately 3.8 million. The majority are male and aged over 65 years. Furthermore, the population of veterans was estimated to halve between 2007 and 2027 due to fewer numbers in the oldest age groups (65-74 and 75+ years in males and 75+ in females). For males this represents those conscripted as national service personnel between the beginning of World War II and 1960. By 2027, the 65-74 and 75+ year age groups are expected to comprise a smaller proportion of the veteran population, having signed up to the Armed Forces after the end of conscription in 1960 . The veteran population size is, therefore, likely to reduce as deaths in the oldest age groups of national service veterans outnumber the number of new veterans leaving the services.

The reductions expected to occur in the 35-44 and 45-54 years groups are likely to be a reflection of the 'baby boom' generation as they move into the older age groups. The 'baby boom' peaked in 1964 when the Total Fertility Rate (TFR) was 2.95 children per woman, ${ }^{10}$ so the elevated population size would be expected to be reflected in the 55-64 and 65-74 age groups respectively by 2027 .

This decline of the veteran population in the older age groups is likely to be mediated by the continued increases in life expectancy assumed to occur into the future as a result of the assumed future reductions in the mortality rate, ${ }^{11}$ such that later cohorts of veterans are likely to live longer. 2006-based UK general population projections assume that mortality rates will decline, on average over all age groups, by 36.5 per cent for males and 37.0 per cent for females in the 25 -year period between 2006 and 2031 (although slightly less for males in Scotland), and to be higher than average in the oldest age groups. ${ }^{11}$

The predicted increase in the total veteran population aged 16-24 years is driven by a 75.1 per cent increase in this group for males, despite a predicted decline of a similar magnitude in the female veteran population of this age. This may be explained since the majority of people leaving the services, in terms of crude numbers, are males under 25 years old who accounted for 40-47 per cent of the total military outflow between 2001 and 2007..$^{9}$ The large magnitude of the increase, however, is potentially due to an underestimation of the baseline male veteran population, perhaps due to underrepresentation in the original survey, although survey response rates by age and sex were not available to corroborate this. While the largest number of female military personnel who leave are also in the youngest age group, the actual numbers becoming veterans are small, accounting for only 4-5 per cent of the annual outflow between 2001 and $2007 .{ }^{9}$ The large reduction in female veterans in the youngest age group is also potentially an artefact due to inaccuracies in the current veteran population estimates for this group based on the sample data, since the numbers of veterans in this age and sex group are low.

\section{Comparison with RBL figures}

The current population estimates are consistent with RBL veteran population estimates. RBL estimated the size of the veteran population of England to be 3.87 million (Royal British Legion, personal communication, October 2009), and of the UK veteran population to be 4.8 million people, of which the majority ( $~ 84$ per cent) were male. ${ }^{2}$ The RBL report also predicted a $\sim 35$ per cent reduction in the veteran population over 15 years between 2005 and $2020 .^{3}$
Furthermore, while the survey used in the current study asked if respondents had ever served in the Armed Forces or reserve Armed Forces to identify veterans, the survey used by the RBL prompted respondents with different types of military service, stipulating regular, reserve and auxiliary service as well as membership of related institutions such as Mercantile Marines and voluntary societies working directly in support of the Armed Forces. ${ }^{2}$ This may have aided recall such that the current study could underestimate veteran numbers compared to the RBL study. As described in their projection publication, RBL used a different method to project the current veteran population that did not involve the use of a life table. ${ }^{3}$ Further, their study assumed military strength would decline by $\sim 1,000$ personnel per year, whereas this current study used average annual strength values by age and sex using military strength values from DASA. ${ }^{12}$ Consequently, while the outflow figures used in the RBL estimates decline over time as a result of an assumed gradual decline in military strength, the current study assumed the outflow rates would remain constant, since no decline in military strength was assumed.

\section{Limitations}

Current estimates

The APMS sample 4 included only community-dwelling adults, so veterans institutionalised in, for example, care homes or prisons were not counted. The total number of veterans living in communal establishments was estimated to be between approximately 26,200 and 43,500 veterans. This is likely to result in an underestimation of veterans particularly in the oldest age groups since the institutionalised population include a proportionately large number of elderly people, ${ }^{6}$ especially females, and over 60 per cent of the current veteran population is estimated to be over age 65 years. Furthermore, this is likely to underestimate the numbers of veterans at younger ages, since a large proportion of the institutionalised population are males aged 20-34 years, some of whom may be in prison. Estimates of the number of ex-service personnel in prison in England and Wales range from $\sim 4,200$ to $\sim 16,700$ veterans, ${ }^{13}$ and a survey of ten prisons within England and Wales estimated that 9.1 per cent of prisoners were ex-service personnel, relating to approximately 7,400 prisoners in England and Wales. ${ }^{13}$ The estimate of the number of veterans living in communal establishments is based on 2001 Census data. Inter censal figures have not been published, and thus may not fully reflect 2007 figures.

The response rate for the APMS survey was 57 per cent. This may bias estimations. For example veterans may be less likely to respond; this may result in an underestimation of the number of veterans.

The military outflow figures used ${ }^{9}$ relate to regular forces; if reservists had been included the number of veterans added to the veteran population would be higher. Furthermore, veterans may be concentrated around military bases; ${ }^{2}$ if so, over-sampling these areas would provide a more accurate population estimation, although the effect is likely to be small.

\section{Projections}

A current life table was used to project the veteran population over a 20 -year period, assuming no change in mortality. However, it is assumed that mortality rates in the UK will continue to decrease over time, ${ }^{11}$ particularly in the older age groups, thus projected estimates of veteran numbers in these groups may be an underestimate. Factors that suggest the veteran population mortality rate may exceed that of the general population relate to the tendency for the Armed Forces (particularly the Army) to recruit from areas with greater socio-economic and social deprivation, including lower educational levels, such that they may exhibit more risky behaviours. ${ }^{14,15}$ However, while alcohol consumption and misuse has been found to be higher in the UK military than in the general population, ${ }^{16}$ the prevalence of smoking has not been found to differ from the general population, ${ }^{17}$ nor have suicide rates among military service leavers, except in the youngest age groups $\left(\leq 24\right.$ years). ${ }^{18}$ 
Evidence from DASA ${ }^{19}$ suggests that veterans of the 1991 Gulf war, and personnel who had served during that time but were not deployed to the Gulf war (Era cohort), have lower disease-related mortality rates between 1991 and 2005 than a comparable UK general population cohort. Deaths from external causes during this time however did not significantly differ between civilians and veterans. ${ }^{19}$ If the reduced mortality rates are generalisable to other veterans in England, and continues into the future, then this is also likely to mean the current and projected population approximations underestimate the veteran population.

In contrast, since the military population has to reach a certain standard of fitness and pass medical examinations as part of their recruitment, they can be expected to be fitter (at least at recruitment) than the general population (the 'healthy soldier' effect) ${ }^{20}$ thus potentially reducing mortality rates compared to the general population. These factors may counteract each other such that any discrepancy between the mortality rates in the general and military population is reduced, thus supporting the assumptions made.

\section{Consequences and further research}

The age distribution of the current veteran population is skewed towards older ages compared to the general population. While the future veteran population is expected to be proportionately younger than it is at present, the age distribution will likely remain skewed towards older age groups. The predicted decline in the veteran population may mean that fewer resources are required to support them. However, as the veteran population will comprise a greater proportion of younger veterans, their needs will differ from the majority of veterans today, for example, in terms of finding employment and marital/relationship counselling. Furthermore, veterans of different conflicts, such as in Iraq and Afghanistan, as well as the Gulf war, the Falklands war, the Korean war and World War II, are likely to have different needs due to the diverse nature of each conflict and the contexts in which they were fought.

The demand for veteran-specific mental health care may increase in future as veterans may be more likely to seek help for mental health related problems, for example, due to current and ongoing initiatives in the UK Armed Forces that attempt to reduce the stigma associated with mental health and treatment seeking. ${ }^{21,22}$

\section{Conclusions}

The veteran population of England is currently estimated at approximately 3.8 million people, and is predicted to decline over the next 20 years. Error in population estimation estimates and projections tends to underestimate veteran population numbers. In order to obtain more accurate estimates of the veteran population, it would be optimal to include questions on military service in all major large-scale national surveys, for example the Health Survey for England.

\section{References}

1 Richardson C and Waldrop J (2003) Veterans: 2000: census 2000 brief, US Census Bureau, Washington DC. Available at: www.census.gov/prod/2003pubs/c2kbr-22.pdf
2 The Royal British Legion (2005) Profile of the ex-service community in the UK.

3 The Royal British Legion (2006) Future profile and welfare needs of the ex-service community.

4 McManus S, Meltzer H, Brugha T, Bebbington P and Jenkins R (2009) Adult Psychiatric Morbidity in England, 2007: results of a household survey. Available at: www.ic.nhs.uk/pubs/psychiatricmorbidity07

5 Office for National Statistics. Mid-2007 population estimates for England and Wales, Scotland and Northern Ireland. Available at: www.statistics.gov.uk/statbase/Product.asp?vlnk=15106

6 Office for National Statistics. 2001 Census. Table S126 - Type of communal establishments and sex by resident type and age. Available at: https://www.nomisweb.co.uk/Default.asp

7 Office for National Statistics. Interim life tables, England. Available at: www.statistics.gov.uk/downloads/theme_population/Interim_Life/ ILTEng0507Reg.xls\#'2004-06'!A1

8 Rowland DT (2003) Demographic methods and concepts. Oxford University Press. New York.

9 TSP 19 UK Regular forces intake and outflow by age (yearly publication). Available at: www.dasa.mod.uk/.

10 Jeffries J (2008) Fertility assumptions for the 2006-based national population projections, Population Trends, 131, 19-27. Available at: www.statistics.gov.uk/articles/population_trends/ PT131FertilAssumptionsNationalPopProj.pdf

11 Government Actuary's Department. Mortality assumptions. Available at: www.gad.gov.uk/Demography\%20Data/ Population/2006/methodology/mortass.html

12 TSP 8 Age distribution of UK Regular forces (yearly publication). Available at: www.dasa.mod.uk/

13 The National Association of Probation Officers (NAPO). Ex-Armed Forces personnel and the criminal justice system. Available at: www.napo.org.uk/cgi-bin/dbman/db.cgi? $\mathrm{db}=$ default\&uid= default\&ID $=187 \&$ view_records $=1 \& w w=1$

14 Johnstone J (1978) Social class, social areas and delinquency, Sociology and Social Research, 63, 49-72.

15 Iversen AC, Fear NT, Simonoff E, Hull L, Horn O, Greenberg N, Hotopf M, Rona R and Wessely S (2007) Influence of childhood adversity on health among male UK military personnel, British Journal of Psychiatry, 191, 506-511.

16 Fear NT, Iversen I, Meltzer H, Workman L, Hull L, Greenberg N, Barker C, Browne T, Earnshaw M, Horn O, Jones M, Murphy D, Rona RJ, Hotopf M and Wessely S (2007) Patterns of drinking in the UK Armed Forces, Addiction, 102, 1749-1759.

17 Fear NT, Horn O, Hull L, Murphy D, Jones M, Browne T, Hotopf M, Wessely S and Rona RJ (submitted) Smoking in the UK Armed Forces: Changes over a seven year period.

18 Kapur N, While D, Blatchley N, Bray I and Harrison K (2009) Suicide after leaving the UK Armed Forces - a cohort study, PLOS Medicine, 6(3), e1000026. doi:10.1371/journal.pmed.1000026

19 UK Defence Statistics (2008). Chapter 3: Health. Available at: www.dasa.mod.uk/UKDS2008/pdf/CHAPTER3.pdf

20 Kang HK and Bullman TA (1996) Mortality among U.S. veterans of the Persian Gulf War, N Engl J Med, 335, 1498-1504.

21 Battlemind UK trial. Available at: www.kcl.ac.uk/kcmhr/acdmh/battlemind.html

22 Greenberg N, Langston V and Jones N (2008) Trauma risk management (TRiM) in the UK Armed Forces, J R Army Med Corps, 154(2), 124-127. 